1 Department of Primary Care \& Public Health, Imperial College London.

Twitter @Azeem_Majeed

Cite this as: BMJ 2022;376:028

http://dx.doi.org/10.1136/bmj.o28

Published: 07 January 2022

\title{
It's time for more targeted use of lateral flow tests for covid-19
}

\author{
Azeem Majeed professor of primary care and public health ${ }^{1}$
}

Lateral flow tests for covid-19 that give a result quickly are a key part of the government's plans to manage the covid-19 pandemic in England. ${ }^{1}$ They are required for key workers such as NHS staff; and for people following guidance from Test and Trace, either because they have a covid-19 infection or have been a close contact of a covid-19 case. The government also announced recently that other groups of workers in essential industries would be required to carry out regular lateral flow tests. ${ }^{2}$ This would be in addition to the tests required by other groups, such as school children.

And yet, despite their potential value, the government has been distributing the tests in a very haphazard fashion; with the outcome that many groups-such as NHS staff-are complaining that they are unable to obtain tests. ${ }^{3}$ Meanwhile, other groups of people have been using the tests excessively-including families carrying out daily tests on each family member and in some cases, carrying out multiple tests each day. People have also been using the tests to "monitor" themselves daily after a positive PCR result for covid-19; something that is not currently required except for tests on day 6 and day 7 of the isolation period in fully vaccinated people.

As with any area of healthcare, the NHS in England has a limit on the number of lateral flow tests it can offer. Earlier this month, the government stated it was delivering 300 million tests per month. ${ }^{4}$ However, even 300 million tests each month (around 10 million tests per day) is nowhere near enough to offer everyone in England a daily lateral flow test. Hence, an appropriate system is needed for prioritising who should have access to the tests; and how the tests are supplied to these groups. The current system whereby most people obtain their tests from the government's online ordering system means that the tests may not always be used appropriately, or by the people who have the highest priority for testing.

The NHS already has well established systems for prioritising access to health services. We saw this, for example, with the covid-19 vaccination programme when early access to vaccination was based on clinical need and for occupational protection. ${ }^{5}$ This meant that the elderly, the clinically vulnerable, and those working in healthcare had the earliest access to vaccination. The same process has not happened in prioritising access to lateral flow tests. Given the high cost of supplying tests to England's population and their limited global availability, as more countries aim to increase their own use of the test in the face of the wave of infection from the SARS-CoV-2 omicron variant, it's essential for the government to reconsider its policies on community covid-19 testing.

The government is in part responsible for the increased demand for testing from the public that has led to the current shortage of tests. It has encouraged members of the public to test regularly; for example, before social events such as parties; and before meeting friends and family from outside their immediate household. However, it has not offered clear guidance on how frequently to test. NHS staff, for example, are only advised to test twice weekly; far less than some members of the public are currently doing even though they have no medical or occupational reason to test more frequently.

How can we improve how well lateral flow tests are used? As a first step, the government needs to decide what groups should be prioritised for testing and how frequently they should test. Once the size of these groups and their frequency of testing are known, the government can allocate a large enough sample of tests to meet their needs. Priority groups for access to lateral flow tests will include NHS staff in patient-facing roles; other key workers such as the police and fire service; workers in essential parts of the economy such as public transport; carers of vulnerable people and people working in social care; and people following guidance from Test and Trace. Tests are also needed by schools where testing of pupils is taking place.

We also need to look at the costs of supplying these tests and determine what we can afford to spend on them. Although the tests are supplied at no cost to the public, they are not free and will come at a considerable cost to the taxpayer. Access to diagnostic services and other health services always has to be limited; and based on factors such as clinical need, health outcomes, and cost-effectiveness. The same rules should apply to lateral flow tests so that the maximum benefit is obtained from spending on covid-19 tests. ${ }^{6}$

With the UK now facing record numbers of people with covid-19, we need the government to act quickly, decisively, and rationally to ensure we maximise the benefits of England's covid-19 testing capacity. Lateral flow tests can play an important role in England's pandemic response, but the same principles of prioritisation should apply in their use as in any other area of healthcare provision.

Competing interests: I have read and understood the BMJ policy on declaration of interests. I have no competing interests.

Acknowledgments: AM is supported by the NIHR Applied Research Collaboration NW London. The views expressed are those of the authors and not necessarily those of the NHS, the NIHR or the Department of Health and Social Care.

Provenance and peer review: commissioned, not peer reviewed

Majeed A. Questions and Answers about Lateral Flow Tests for Covid-19. https://blogs.imperial.ac.uk/medical-centre/2021/12/23/questions-and-answers-about-lateral-flow-tests-for-covid-19/

Walker P. 100000 key workers in England told to take Covid test every working day. https://www.theguardian.com/world/2022/jan/04/100000key-workers-in-england-told-to-take-covid-test-every-working-day 


\section{OPINION}

3 Majeed A. Of course England is running out of Covid tests-the strategy is a flawed one. https://www.theguardian.com/commentisfree/2021/dec/30/running-out-covid-tests-strategyflawed

4 Johnson B. PM statement to the House of Commons on COVID-19: 5 January 2022.

https://www.gov.uk/government/speeches/pm-statement-to-the-house-of-commons-on-covid19-5-january-2022

5 Majeed A, Molokhia M. Vaccinating the UK against covid-19 BMJ 2020:371:m4654 doi: 10.1136/bmj.m4654

6 Raffle AE, Gill M. Mass screening for asymptomatic SARS-CoV-2 infection. BMJ2021;373:n1058. doi: 10.1136/bmj.n1058. pmid: 33910784 